\title{
Vibro-base isolation of a building to decrease the technical seismicity effect
}

\author{
D. Makovička ${ }^{1} \&$ D. Makovička Jr. ${ }^{2}$ \\ ${ }^{1}$ Czech Technical University in Prague, Klokner Institute, Czech Republic \\ ${ }^{2}$ Static and Dynamic Consulting, Czech Republic
}

\begin{abstract}
When vehicles run on underground and above-ground roads, vibrations propagate from the traffic structures to the buildings in their vicinity. These vibrations are designated as technical seismicity from traffic effects. Vibro-base isolation is a promising method for reducing the vibrations of buildings (Makovička and Makovička, Structure insulation exposed to excessive vibration of underground traffic (2005) and Jacquet and Heiland Tieffrequente BauwerkenKopplungen als Schutz gegen Erschütterungen (2002)). A layer of rubber or some other elastomer is usually used for this purpose. This elastic layer is located between the twinned foundation base plate. In order to help engineers decide whether to implement vibro-isolation, a comparison is made between the response of a building with vibro-isolation and without vibro-isolation. A further aim of the paper is to use an example of a concrete structure to present the effectiveness of vibro-base isolation, namely by comparing vibration measurements before and after construction of the building. Free-field measurements, calculation prognosis of vibration and final vibration measurements on the residential floors of the building are compared and discussed.
\end{abstract}

Keywords: technical seismicity, vibro-base isolation, elastomer, dynamic analysis, measurement, validation.

\section{Introduction}

A calculation model (Fig. 1) of an entire structure was designed for an analysis of the structure, including the underground storeys and the vibro-isolation rubber layer. The computational model is placed on a multiple-layer subsoil structure, 
on the level of the floor of the $3^{\text {rd }}$ underground storey, the computational model is placed on a multiple-layer subsoil structure.

The foundation plate $500 \mathrm{~mm}$ in thickness (upper foundation plate) is placed on a vibro-isolation layer made of Ekodyn rubber blocks (Makovička and Makovička [1]). The bottom concrete $150 \mathrm{~mm}$ in thickness (lower foundation plate) is placed below the rubber layer, which is laid on a layer of the original healthy slate subsoil (class R3). The footing bottom is below the underground water level. The relative structure damping value was chosen as $5 \%$ of the critical damping value.

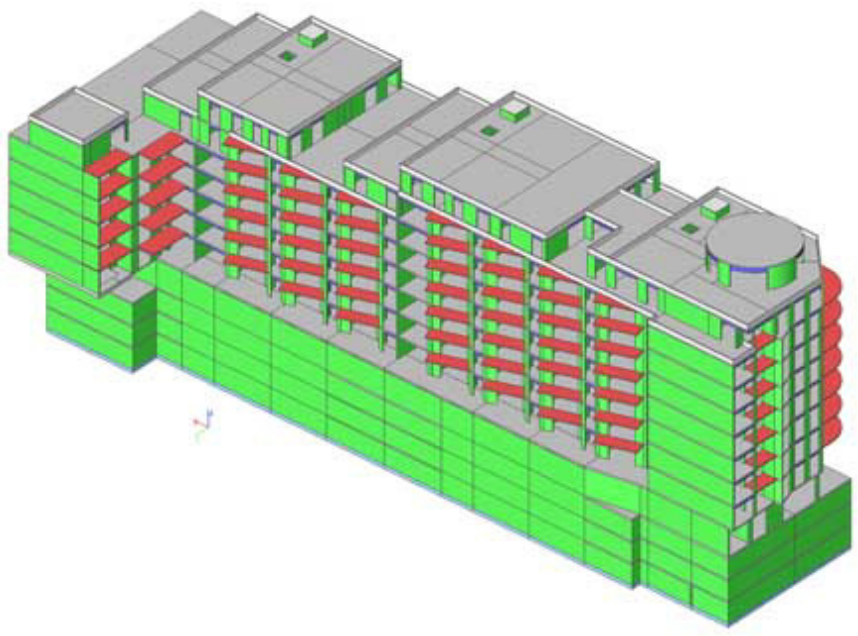

Figure 1: Calculation model of the building (south-west view).

Non-stationary dynamic excitation (Fig. 2) due to traffic was introduced to the model at selected points of the structure, in an approximately regular grid of points on the level of the foundation plate. Attenuation of the dynamic excitation along the distance from the source was introduced to the structure model in steps, using bands approximately $10 \mathrm{~m}$ in width, graduated on the basis of measured vibrations.

A dynamic load was introduced to the structure at the same moment and with the same phase. Part of the measured acceleration record, incorporating the effect of metro the passage of an underground train lasting $1 \mathrm{~s}$, was used for the dynamic calculation. This selected $1 \mathrm{~s}$ of the record includes several maximum non-stationary values of the measured acceleration of the vibrations, and corresponds to the maximum excited vibration on a test foundation block inside the area of the structure (free-field measurement).

\section{Structure model}

The building (ground plan size roughly $90 \times 21 \mathrm{~m}$ ) has three underground storeys and six (north side) up to ten (south side) graduated storeys above the ground. The building is founded on a foundation plate on the level of the $3^{\text {rd }}$ underground 
a)

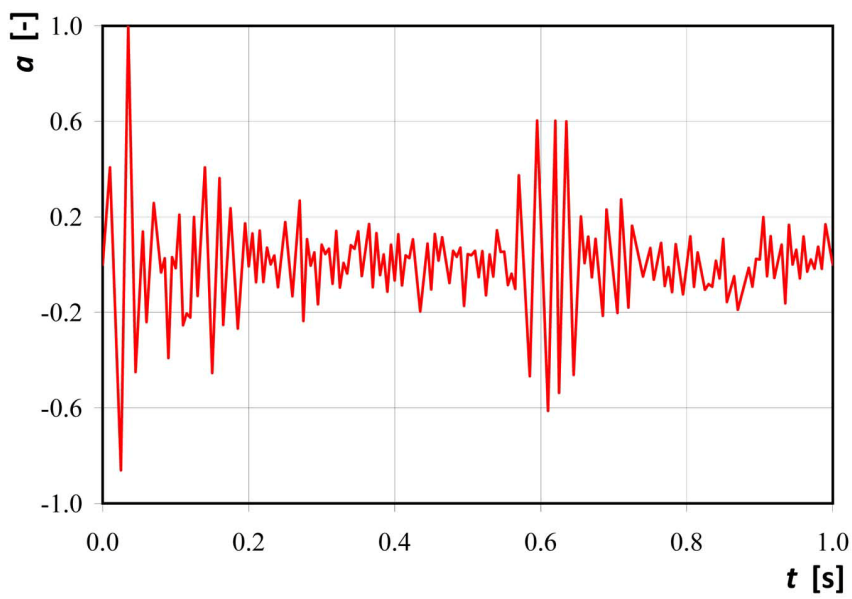

b)

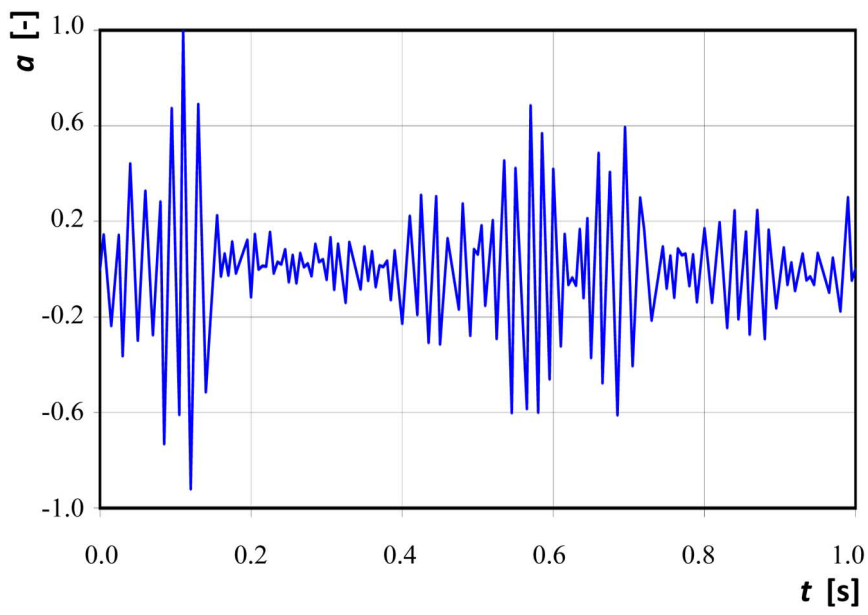

Figure 2: $\quad$ Selected parts of the vibration excitation, a) vertical, b) horizontal.

storey. A 3D model (Fig. 1) was chosen for dynamic analysis of the structure. Floor slabs, load-bearing walls, columns and beams were modelled as reinforced concrete monoliths made of concrete $\mathrm{C} 30 / 37$. The load-bearing walls in the longitudinal direction of the storeys above the ground were modelled as built of bricks. Staircase broadsteps and loggia slabs were simulated as precast slabs, hinge-connected to the walls of the structure. The mass of the floor and the foundation plates includes the masses of the non-loadbearing components (thin partitions, floorings, etc.) as well as the equivalent of the live loads of the floors, roof and terraces.

The anti-vibration layer of the rubber plates was designed in such a way that (a) its response to permanent and long-term loads in deflections is approximately uniform and does not exceed $10 \%$ to $15 \%$ of the rubber thickness (Makovička 
and Makovička [1, 2]). The layer of rubber was considered as the elastic subsoil of the Winkler-Pasternak model below the whole area of the upper part of the foundation plate. The rubber stiffness in the theoretical model takes into account the results of experimental tests on these materials.

\section{Natural vibrations}

The natural vibration of the residential building was calculated for the model of the whole structure laid on the elastic vibro-isolation layer. In terms of the dynamic response of the building to the effects of the dynamic load (traffic), the lowest possible tuning of the building structure is decisive.

This is manifested by the flexural vibration of the building on the rubber, on the one hand, and by the vertical and horizontal translative vibration of the
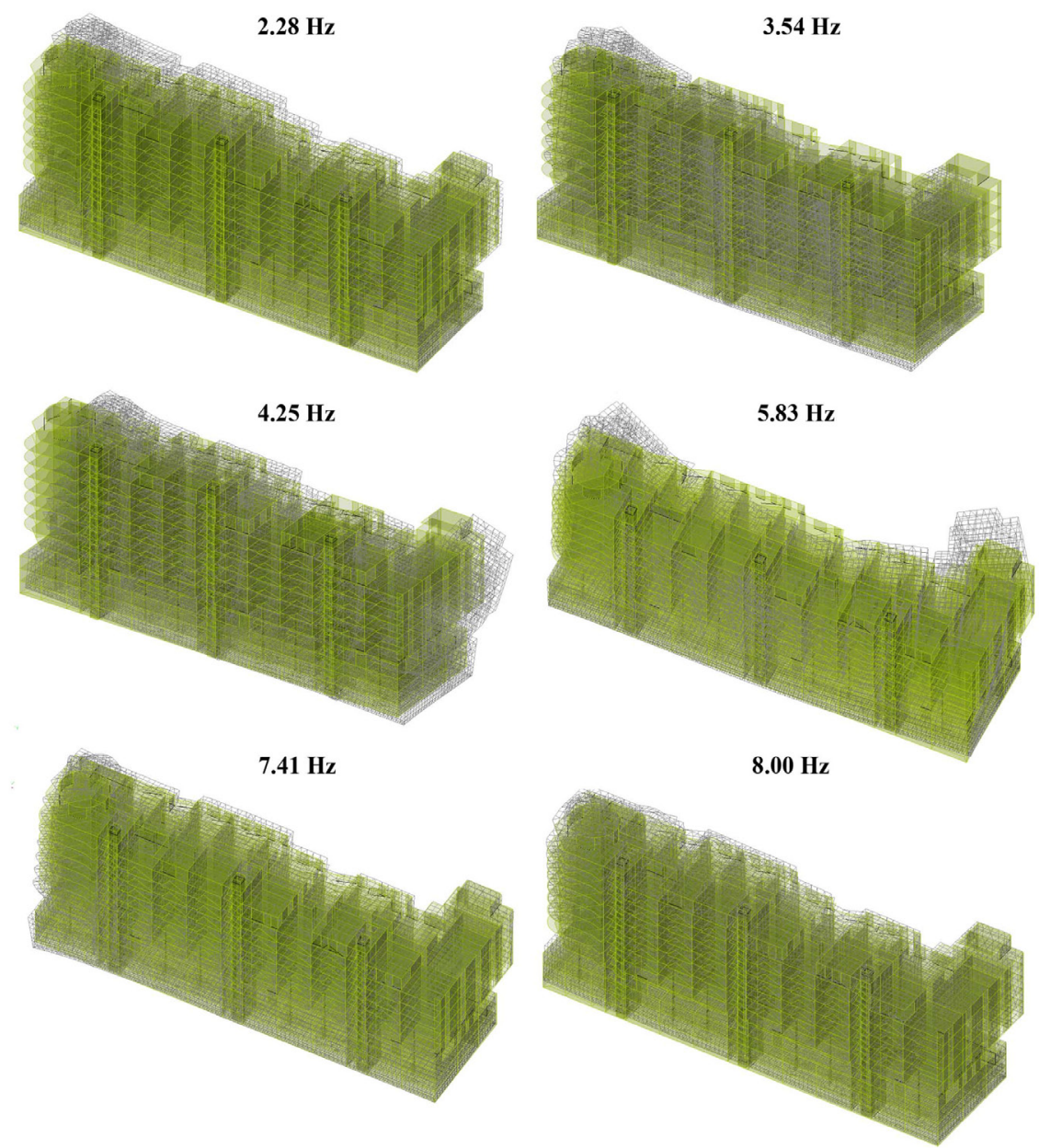

Figure 3: Natural vibration modes and frequencies of the building. 
building as a whole on the rubber, or by the torsional vibration of the whole structure or parts of it. For illustration, the six lowest natural vibration modes are arranged in Fig. 3. The first 75 natural modes were used for the dynamic calculation of forced vibration.

\section{Forced vibrations}

The forced vibration of the structure was calculated using the method of decomposing the dynamic excitation to the spectrum of natural vibration modes. The calculation determined the dynamic response of the structure, while the overall duration of the calculation was $1.000 \mathrm{~s}$, and the calculation was made with a step of $0.005 \mathrm{~s}$.

The calculated values (displacements of the foundation plate and floor slabs) were normalized so that the maximum displacement value in the foundation plate was equal to 1 . For comparison, the response of the structure to dynamic load was also calculated for the isolated and non-isolated structure; the resulting normalized values in the displacements caused by vertical and horizontal excitation are shown in Tab. 1.

In the case of rigid foundation of the building, on piles or on a foundation plate without isolation, the vibrations would propagate from the subsoil directly into the RC building structure, practically without decreasing.

Fig. 4 shows the resulting time histories of the calculated response for selected points within a vertical axis located in the central part of the building

Table 1: $\quad$ Extremes of relative floor displacements.

\begin{tabular}{|c|c|c|c|c|c|c|c|c|}
\hline \multirow{4}{*}{$\begin{array}{l}\text { Floor } \\
\text { level }\end{array}$} & \multicolumn{4}{|c|}{ Isolated structure } & \multicolumn{4}{|c|}{ Non-isolated structure } \\
\hline & \multirow{2}{*}{\multicolumn{2}{|c|}{$\frac{\begin{array}{c}\text { vertical } \\
\text { excitation }\end{array}}{u_{\mathrm{z}}}$}} & \multirow{2}{*}{\multicolumn{2}{|c|}{ 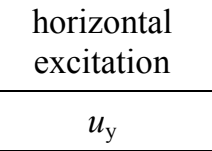 }} & \multirow{2}{*}{\multicolumn{2}{|c|}{$\frac{\begin{array}{c}\text { vertical } \\
\text { excitation }\end{array}}{u_{\mathrm{z}}}$}} & \multirow{2}{*}{\multicolumn{2}{|c|}{$\begin{array}{c}\begin{array}{c}\text { horizontal } \\
\text { excitation }\end{array} \\
u_{\mathrm{y}}\end{array}$}} \\
\hline & & & & & & & & \\
\hline & $\max$ & $\min$ & $\max$ & $\min$ & $\max$ & $\min$ & $\max$ & $\min$ \\
\hline$-3^{\text {rd }}$ Floor & +1.00 & -0.76 & +1.00 & -0.83 & +1.00 & -1.00 & +1.00 & -1.00 \\
\hline$-2^{\text {nd }}$ Floor & +1.22 & -1.29 & +0.96 & -1.07 & +1.43 & -1.00 & +1.28 & -1.89 \\
\hline$-1^{\text {st }}$ Floor & +1.24 & -0.97 & +0.89 & -0.89 & +1.00 & -1.00 & +1.12 & -1.23 \\
\hline$+1^{\text {st }}$ Floor & +0.87 & -0.92 & +0.70 & -0.59 & +0.85 & -0.82 & +1.18 & -1.49 \\
\hline$+2^{\text {nd }}$ Floor & +0.74 & -0.64 & +1.00 & -1.02 & +0.70 & -0.53 & +0.85 & -0.91 \\
\hline$+3^{\text {rd }}$ Floor & +0.70 & -0.69 & +0.85 & -0.76 & +0.54 & -0.72 & +0.91 & -0.95 \\
\hline$+4^{\text {th }}$ Floor & +0.73 & -0.72 & +1.80 & -1.13 & +0.63 & -0.51 & +0.81 & -1.04 \\
\hline$+5^{\text {th }}$ Floor & +0.66 & -0.66 & +1.80 & -0.93 & +0.63 & -0.56 & +0.81 & -1.19 \\
\hline$+6^{\text {th }}$ Floor & +0.69 & -0.71 & +0.85 & -1.04 & +0.52 & -0.47 & +1.90 & -1.32 \\
\hline
\end{tabular}


a)

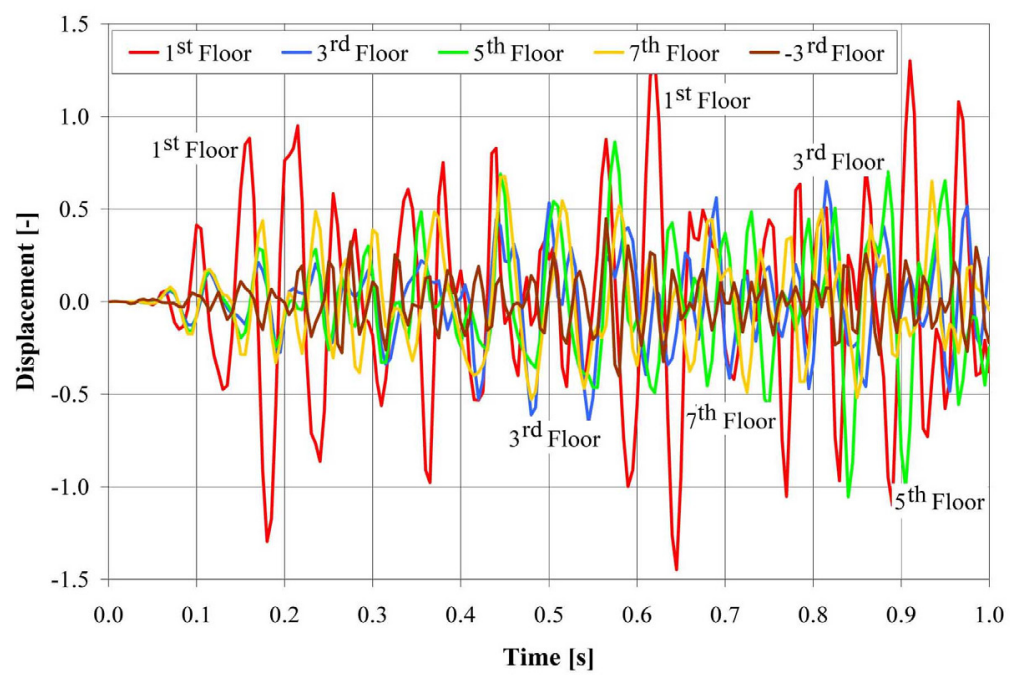

b)

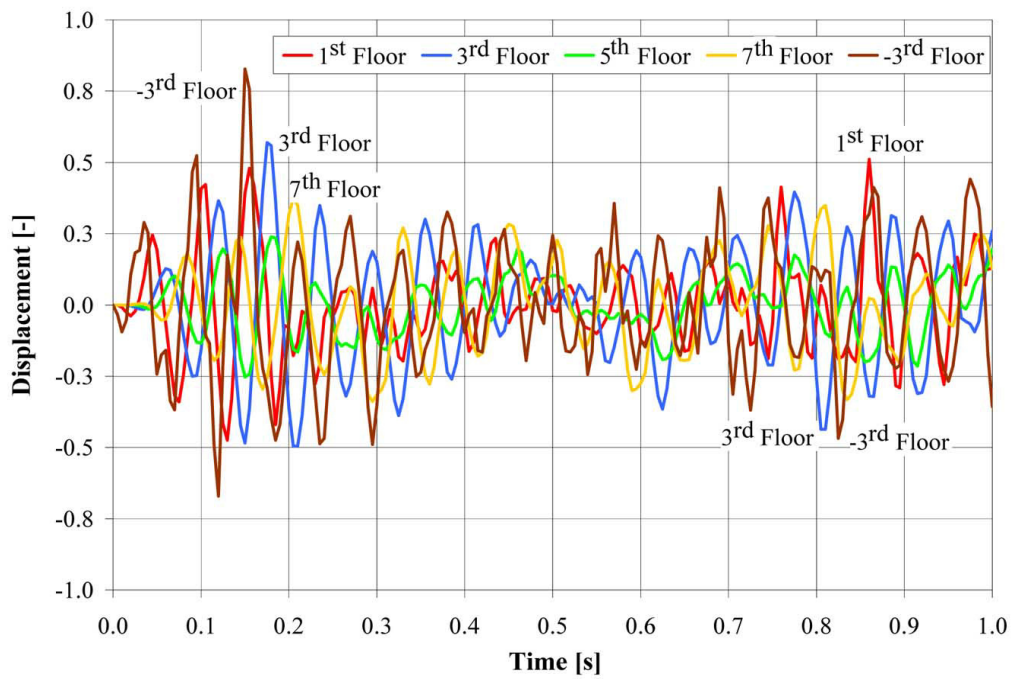

Figure 4: Time histories of relative displacements, a) vertical, b) horizontal.

almost above the underground tube structure in the vicinity of the west corner of the building. The most intensively vibrating points are found near the underground floors and in the lowest one or two aboveground storeys in parts of the structure that are spatially situated toward the side of the underground tube. With rising height of the building, the dynamic response on particular floor levels decreases in cases where the mass and stiffness of the higher storeys are comparable. This effect manifests mainly on the lowest natural vibration modes, because the inertia of a substantial part of the structure is relative high, and the 
compliance of this part of the building at lower frequencies is low. The time histories indicate that the frequency range of the response in the displacements is shifted to the lower frequency range.

\section{Validation of the calculated vibration prognosis}

Based on vibration measurements before and after construction, the maximum measured vibrations are shown in the Table 2 . The vibration prognosis in the design stage of the building is also given in this table, for a comparison of all of this data.

Fig. 5 presents the one-third-octave frequency spectra in acceleration for two records. The first spectrum (Fig. 5a) corresponds to one measurement record in

a)

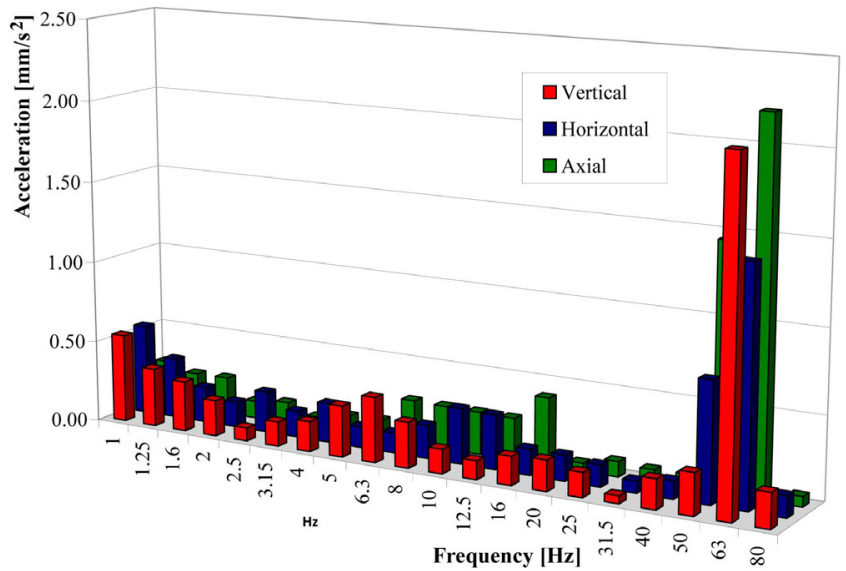

b)

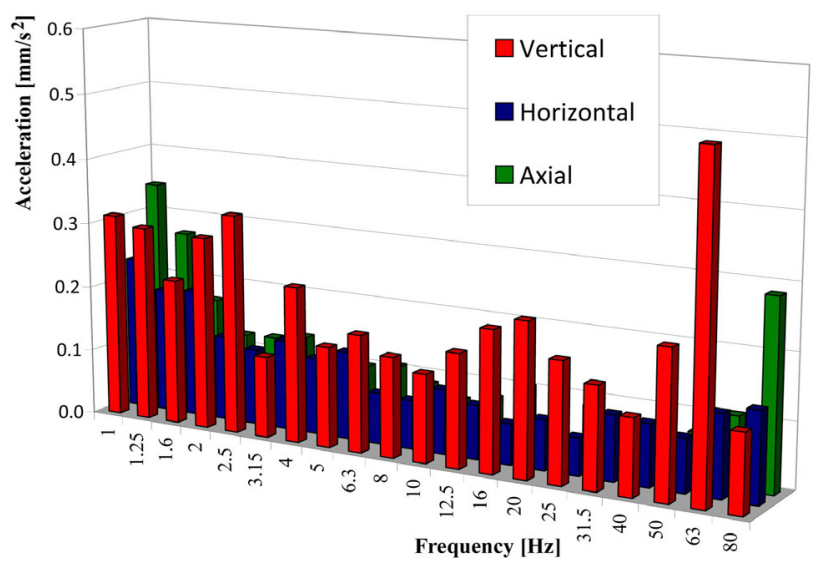

Figure 5: One-third-octave frequency spectra in acceleration before (a) and after (b) construction of the building. 
free-field conditions, and the second spectrum (Fig. 5b) corresponds to the other record, but at a stage when the building is almost finished. The frequency spectrum (Fig. 5b) clearly indicates that the dominant vibrations of the building are found in the area of low frequencies, and correspond to the building tuned as a whole on rubber vibro-isolation.

Table 2: Comparison of measured vibrations and calculation prognosis in acceleration $\left[\mathrm{mm} / \mathrm{s}^{2}\right]$.

\begin{tabular}{|c|c|c|c|}
\hline Period of construction & vertical & horizontal & axial \\
\hline \multicolumn{4}{|c|}{ Peak value of acceleration (maximum) } \\
\hline free-field measurement & 33.6 & 51.9 & 62.2 \\
\hline measurement after construction & 15.4 & 6.2 & 8.9 \\
\hline \multicolumn{4}{|c|}{ Effective value of acceleration (maximum in the interval 1 to $20 \mathrm{~Hz}$ ) } \\
\hline free-field measurement & 0.80 & 0.59 & 0.79 \\
\hline calculation prognosis & 0.98 & 0.13 & 0.25 \\
\hline measurement after construction & 0.31 & 0.23 & 0.34 \\
\hline
\end{tabular}

Table 2 compares the effective measured accelerations of the vibrations with vibration prognosis by calculation. The comparison clearly indicates that the measured vertical vibrations are lower than the values that would correspond to the prognosis and the initial free-field measurement. The consensus of the measured horizontal and axial accelerations and the vibration prognosis in these two directions shows that the prognosis is slightly better than the real situation after the structure has been completed, but the reduction in vibration between the initial and final measurements remains very good.

Table 2 and Fig. 5 therefore show that the application of vibro-isolation is a very efficient way to reduce the transfer of vibration (Makovička, 2009, Kay, 2001) from the subsoil to the interior parts of the building.

\section{Conclusion}

In this paper we set out to assess the effect of building vibro-isolation on the transfer of vibrations due to traffic from the subsoil environment. The maximum measured intensities of the vibrations at the construction site were used as a nonperiodic load of the building by technical seismicity caused by traffic effects. Optimum distribution of the vibro-isolation in the foundation structure was designed on the basis of a calculation of the static and dynamic response of the building. The calculation was also used to predict the floor vibration on individual storeys, and the time courses of the vibration at selected points were determined. 
The paper has compared the calculated responses for an isolated building and a non-isolated building. The computed vibration histories of the examined building reveal that the vibrations of the isolated structure are decreased in all the above-ground storeys. The effectiveness of the vibro-isolation is determined by the frequency tuning of the isolated structure.

The calculated vibration forecast was compared with the final measurement results after the building was constructed (Table 2). This measurement indicated good agreement between prognosis and final observations. The frequency spectra in Fig. 5 show clearly that the main reason for the reduction in vibration is the shift of the excitation frequencies in the soil medium to the lower interval of frequencies of the vibration response due to the vibro-base isolation of the whole building.

\section{Acknowledgement}

This research has been supported as a part of the research projects in the framework of GAČR 103/08/0859 "Structure response under static and dynamic loads caused by natural and man-induced activity", for which the authors would like to thank the Agency.

\section{References}

[1] Makovička, D. \& Makovička, D., Jr., Response analysis and vibroinsulation of buildings subject to technical seismicity, Earthquake Resistant Engineering Structures VII, WIT Press, Southampton, UK, pp. 197-205, 2009.

[2] Makovička, D. \& Makovička, D., Jr., Structure insulation exposed to excessive vibration of underground traffic (in Czech), Stavebni obzor, 14/1, 2005.

[3] Jacquet, T. \& Heiland, D., Tieffrequente Bauwerken-Kopplungen als Schutz gegen Erschütterungen, Gerb Berlin, 2002.

[4] Kay, H., Nachträgliche Schwingungsisolierungen von Gebäuden, Spezialtiefbau, TIS 2001, No. 4. 